ARTICLE

\title{
A nine-atom rhodium-aluminum oxide cluster oxidizes five carbon monoxide molecules
}

Xiao-Na Li ${ }^{1}$, Hua-Min Zhang ${ }^{1}$, Zhen Yuan ${ }^{1,2} \&$ Sheng-Gui He ${ }^{1}$

Noble metals can promote the direct participation of lattice oxygen of very stable oxide materials such as aluminum oxide, to oxidize reactant molecules, while the fundamental mechanism of noble metal catalysis is elusive. Here we report that a single atom of rhodium, a powerful noble metal catalyst, can promote the transfer of five oxygen atoms to oxidize carbon monoxide from a nine-atom rhodium-aluminum oxide cluster. This is a sharp improvement in the field of cluster science where the transfer of at most two oxygen atoms from a doped cluster is more commonly observed. Rhodium functions not only as the preferred trapping site to anchor and oxidize carbon monoxide by the oxygen atoms in direct connection with rhodium but also the primarily oxidative centre to accumulate the large amounts of electrons and the polarity of rhodium is ultimately transformed from positive to negative.

\footnotetext{
${ }^{1}$ Beijing National Laboratory for Molecular Sciences, State Key Laboratory for Structural Chemistry of Unstable and Stable Species, Institute of Chemistry, Chinese Academy of Sciences, Zhongguancun North First Street 2, Beijing 100190, China. ${ }^{2}$ University of Chinese Academy of Sciences, Beijing 100049 ,

China. Correspondence and requests for materials should be addressed to S.-G.H. (email: shengguihe@iccas.ac.cn).
} 
O xide-supported rhodium ( $\mathrm{Rh})$ exhibits extraordinary catalytic activity in a large number of reactions ${ }^{1-9}$ such as the oxidation of carbon monoxide $(\mathrm{CO})^{1-3,7}$, carbon dioxide methanation ${ }^{6}$, partial oxidation of methane to syngas ${ }^{4,5,8,9}$ and so on. It has been reported that trace amounts of $\mathrm{Rh}$ can promote direct participation of lattice oxygen of chemically very inert supports such as aluminum oxide $\left(\mathrm{Al}_{2} \mathrm{O}_{3}\right)$, to oxidize reactant molecules ${ }^{4,5,9}$, while the fundamental mechanism is elusive. Exploring the function of $\mathrm{Rh}$ in invoking the lattice oxygen of oxide support is of great importance to understand heterogeneous catalysis but remains a big challenge because of the structure complexity of bulk material.

Atomic clusters are considered as the intermediate matter to bridge atoms and their bulk counterpart ${ }^{10}$, and can be ideal models for active sites of condensed-phase system. Cluster reactions ${ }^{11-17}$ can be studied under isolated conditions to provide the mechanistic insights of elementary steps in the related condensed-phase systems. Important findings such as spin conservation $^{13}$ and the complementary active sites ${ }^{15}$ have been revealed by studying the reactions of aluminum clusters with molecular $\mathrm{O}_{2}$ and water, respectively. The oxygen atom transfer (OAT) from metal oxide clusters to small molecules is one type of extensively studied reactions ${ }^{12,18,19}$. Noble metal-doped heteronuclear oxide clusters ${ }^{20}$ are being actively studied to understand the mechanistic nature of supported catalysts in the OAT reactions such as $\mathrm{CO}$ oxidation, an important model

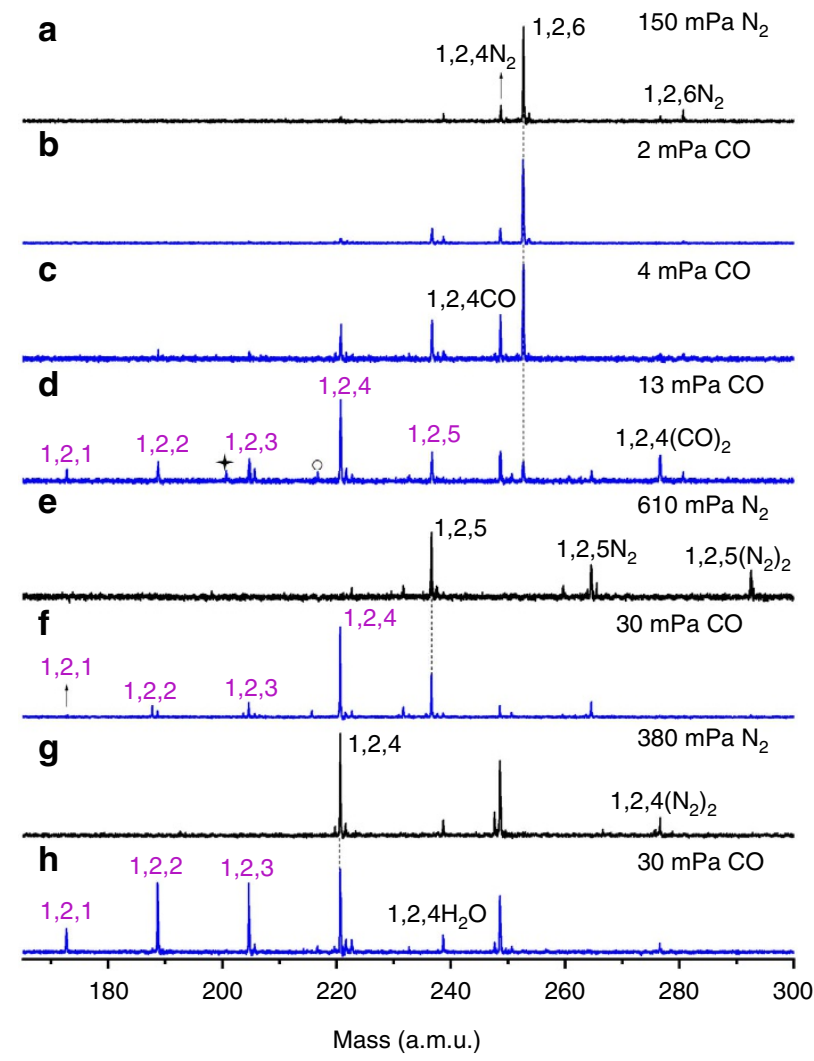

Figure 1 | Reactivity of $\mathbf{R h A l}_{\mathbf{2}} \mathbf{O}_{\mathbf{4 - 6}}{ }^{+}$clusters with CO. Time-of-flight mass spectra for reactions of mass selected $\mathrm{RhAl}_{2} \mathrm{O}_{4-6}{ }^{+}$with $\mathrm{N}_{2}(\mathbf{a}, \mathbf{e}, \mathbf{g})$ and $\mathrm{CO}$ $(\mathbf{b}-\mathbf{d}, \mathbf{f}, \mathbf{h})$ are shown. Peaks marked with asterisk and hollow circle in $\mathbf{d}$ are $\mathrm{CO}$ adsorption products of $\mathrm{RhAl}_{2} \mathrm{OCO}^{+}$and $\mathrm{RhAl}_{2} \mathrm{O}_{2} \mathrm{CO}^{+}$, respectively. $\mathrm{Rh}_{x} \mathrm{Al}_{y} \mathrm{O}_{z}^{+}$and $\mathrm{Rh}_{x} \mathrm{Al}_{y} \mathrm{O}_{z} X^{+}\left(X=\mathrm{N}_{2}, \mathrm{CO}\right.$ and $\left.\mathrm{H}_{2} \mathrm{O}\right)$ species are labeled as $x, y, z$ and $x, y, z X$, respectively. Signal $1,2,4 \mathrm{H}_{2} \mathrm{O}$ in $\mathbf{h}$ is due to the residual water in the gas handling system. The time periods for reactions $\mathrm{RhAl}_{2} \mathrm{O}_{6}^{+}$ $+\mathrm{CO}, \mathrm{RhAl}_{2} \mathrm{O}_{5}^{+}+\mathrm{CO}$ and $\mathrm{RhAl}_{2} \mathrm{O}_{4}^{+}+\mathrm{CO}$ were about 1.1, 0.7 and $0.6 \mathrm{~ms}$, respectively. The reactant gas pressures are shown in $\mathrm{mPa}$. reaction in heterogeneous processes ${ }^{21}$ and its wide applications in air purification. Au and $\mathrm{Pt}$ atoms have been emphasized to be crucial, to promote significantly the efficiency of OAT in CO oxidation $^{22-26}$. However, each of the reported Au or Pt-doped clusters such as $\mathrm{AuAl}_{3} \mathrm{O}_{5}^{+}$and $\mathrm{PtAl}_{3} \mathrm{O}_{7}^{-}$can transfer at most two oxygen atoms to oxidize $\mathrm{CO}$ (refs 22-26). Here we report that a single $\mathrm{Rh}$ atom can unexpectedly promote the transfer of five oxygen atoms to oxidize $\mathrm{CO}$ from a nine-atom cluster $\mathrm{RhAl}_{2} \mathrm{O}_{6}^{+}$, which produces the oxygen very deficient species $\mathrm{RhAl}_{2} \mathrm{O}^{+}$. In contrast, reported homonuclear aluminum oxide clusters $\left(\mathrm{Al}_{x} \mathrm{O}_{y}^{ \pm}\right)^{26,27}$ can deliver only one oxygen atom to $\mathrm{CO}$ and these reactive clusters such as $\mathrm{Al}_{2} \mathrm{O}_{3}^{+}$and $\mathrm{Al}_{4} \mathrm{O}_{7}^{-}$are all oxygen-rich species. Identification of multiple OAT from a single Rh-atomdoped cluster to reactant molecules is an important step to understand the participation of lattice oxygen promoted by noble metals. This gas-phase study that a nine-atom rhodiumaluminum oxide cluster oxidizes five $\mathrm{CO}$ molecules is a sharp improvement in the field of cluster science and provides a strictly molecular level understanding of the fundamental mechanism of noble metal catalysis in the related condensed phase.

\section{Results}

Reactivity of rhodium-aluminum oxide clusters with $\mathrm{CO}$. The $\mathrm{RhAl}_{2} \mathrm{O}_{m}^{+}(m=2-6)$ cluster ions were generated by laser ablation of a mixed-metal disk compressed with $\mathrm{Rh}$ and $\mathrm{Al}$ powders. The generated $\mathrm{RhAl}_{2} \mathrm{O}_{m}^{+}$cluster ions were mass-selected, cooled and then interacted with $\mathrm{N}_{2}$ and $\mathrm{CO}$ in an ion trap reactor, as shown in Figs 1 and 2. On the interaction of $\mathrm{RhAl}_{2} \mathrm{O}_{6}^{+}$with $150 \mathrm{mPa} \mathrm{N}$ (Fig. 1a), weak $\mathrm{N}_{2}$ adsorption $\left(\mathrm{RhAl}_{2} \mathrm{O}_{6} \mathrm{~N}_{2}^{+}\right)$and $\mathrm{N}_{2} / \mathrm{O}_{2}$ exchange $\left(\mathrm{RhAl}_{2} \mathrm{O}_{4} \mathrm{~N}_{2}^{+}\right)$products were generated. Generation of $\mathrm{RhAl}_{2} \mathrm{O}_{4} \mathrm{~N}_{2}^{+}$suggests the possible presence of superoxide $\left(\mathrm{O}_{2}^{-} \bullet\right)$ or peroxide $\left(\mathrm{O}_{2}^{2-}\right)$ unit in $\mathrm{RhAl}_{2} \mathrm{O}_{6}^{+}\left(\mathrm{RhAl}_{2} \mathrm{O}_{6}^{+}+\mathrm{N}_{2} \rightarrow\right.$ $\mathrm{RhAl}_{2} \mathrm{O}_{4} \mathrm{~N}_{2}^{+}+\mathrm{O}_{2}$ ). In sharp contrast, on the interaction of $\mathrm{RhAl}_{2} \mathrm{O}_{6}^{+}$with $\mathrm{CO}$ (Fig. $1 \mathrm{~b}-\mathrm{d}$ ), a series of products, from $\mathrm{RhAl}_{2} \mathrm{O}_{5}^{+}$to $\mathrm{RhAl}_{2} \mathrm{O}^{+}$, were generated gradually with the increase of $\mathrm{CO}$ partial pressure from 2 to $13 \mathrm{mPa}$. Signals $\mathrm{RhAl}_{2} \mathrm{O}_{1-5}^{+}$did not appear on the interaction of $\mathrm{RhAl}_{2} \mathrm{O}_{6}^{+}$with even high pressure $\mathrm{N}_{2}$ (Fig. 1a). Additional experimental techniques such as multiphoton ionization ${ }^{28,29}$ employing pulsed lasers are required to observe the neutral $\mathrm{CO}_{2}$ molecules. However, $\mathrm{N}_{2}$ experiment in Fig. 1a also indicates that products $\mathrm{RhAl}_{2} \mathrm{O}_{1-5}^{+}$are due to the chemical reactions of $\mathrm{RhAl}_{2} \mathrm{O}_{6}^{+}$with $\mathrm{CO}$ rather than collision-induced dissociation and $\mathrm{RhAl}_{2} \mathrm{O}_{6}^{+}$may oxidize five $\mathrm{CO}$ molecules consecutively (equation (1)).

$$
\mathrm{RhAl}_{2} \mathrm{O}_{m}^{+}+\mathrm{CO} \rightarrow \mathrm{RhAl}_{2} \mathrm{O}_{m-1}^{+}+\mathrm{CO}_{2}(m=6-2)
$$

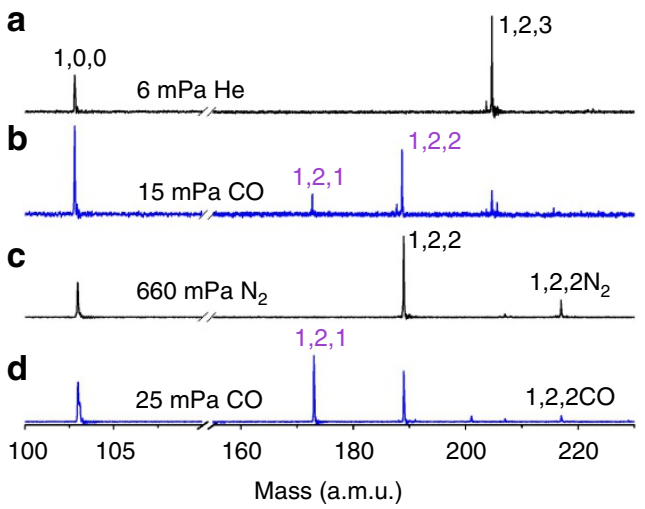

Figure $\mathbf{2}$ | Reactivity of $\mathbf{R h A l}_{\mathbf{2}} \mathbf{O}_{\mathbf{2 - 3}}{ }^{+}$clusters with CO. Time-of-flight mass spectra for reactions of mass selected $\mathrm{RhAl}_{2} \mathrm{O}_{2-3}{ }^{+}$with $\mathrm{He}(\mathbf{a}), \mathrm{N}_{2}$ (c) and $\mathrm{CO}(\mathbf{b}, \mathbf{d})$ are shown. The time period was $\sim 0.6 \mathrm{~ms}$ for both reactions. 
The strong signals that can be assigned as $\mathrm{RhAl}_{2} \mathrm{O}_{4} \mathrm{CO}^{+}$and $\mathrm{RhAl}_{2} \mathrm{O}_{4}(\mathrm{CO})_{2}^{+}$(Fig. 1a-d) on the interaction of $\mathrm{RhAl}_{2} \mathrm{O}_{6}^{+}$with $\mathrm{CO}$ indicate the displacement of the $\mathrm{O}-\mathrm{O}$ unit in $\mathrm{RhAl}_{2} \mathrm{O}_{6}^{+}$by $\mathrm{CO}$, which is more facile than $\mathrm{N}_{2}$ displacement (Fig. 1a), and further demonstrates the presence of $\mathrm{O}_{2}^{-}$or $\mathrm{O}_{2}^{2-}$ unit in $\mathrm{RhAl}_{2} \mathrm{O}_{6}^{+}$. Each of the cluster source generated $\mathrm{RhAl}_{2} \mathrm{O}_{m}^{+}$ $(m=5-2)$ clusters could also react with $\mathrm{CO}$ to generate products, from $\mathrm{RhAl}_{2} \mathrm{O}_{m-1}^{+}$to $\mathrm{RhAl}_{2} \mathrm{O}^{+}$(Figs 1f,h and 2b,d). This provides convincing evidence that $\mathrm{RhAl}_{2} \mathrm{O}_{6}^{+}$can indeed oxidize five $\mathrm{CO}$ molecules consecutively. The pseudo-first-order rate constants $\left(k_{1}\right.$, in unit of $10^{-10} \mathrm{~cm}^{3}$ per molecule per second) on the interaction of $\mathrm{RhAl}_{2} \mathrm{O}_{m}^{+}(m=6-2)$ cluster ions with $\mathrm{CO}$ can be well fitted (Fig. 3) and the determined rate constants are presented in Supplementary Table 1 . The rate constants for the reactions of the cluster source generated $\mathrm{RhAl}_{2} \mathrm{O}_{m}^{+} \quad(m=6-2)$ with $\mathrm{CO}$ are $4.9 \pm 1.5(m=6), 6.2 \pm 1.9(m=5), 1.6 \pm 0.5(m=4)$, $6.9 \pm 2.0(m=3)$ and $2.4 \pm 0.7(m=2)$, which correspond to the reaction efficiencies ${ }^{30}$ of about $(37 \pm 11) \%,(47 \pm 14) \%,(13 \pm 4) \%$, $(54 \pm 16) \%$ and $(19 \pm 6) \%$, respectively. Furthermore, we note that the clusters with odd number of oxygen atoms such as $\mathrm{RhAl}_{2} \mathrm{O}_{5}^{+}$ are more reactive towards $\mathrm{CO}$ oxidation than clusters with even number of oxygen atoms such as $\mathrm{RhAl}_{2} \mathrm{O}_{6}^{+}$.
Reaction mechanism. The density functional theory calculated thermodynamic data for $\mathrm{CO}$ oxidation by $\mathrm{RhAl}_{2} \mathrm{O}_{m}^{+} \quad(m=2-6)$ are shown in Fig. 4. The overall oxidation $\left(\mathrm{RhAl}_{2} \mathrm{O}_{6}^{+}+5 \mathrm{CO} \rightarrow\right.$ $\left.\mathrm{RhAl}_{2} \mathrm{O}^{+}+5 \mathrm{CO}_{2}\right)$ is highly exothermic $(-9.00 \mathrm{eV})$. The lowlying energy isomers of clusters $\mathrm{RhAl}_{2} \mathrm{O}_{m}^{+}(m=6-1)$ are provided in Supplementary Figs 1-6. The lowest energy isomer of $\mathrm{RhAl}_{2} \mathrm{O}_{6}^{+}$is in the triplet spin state (Supplementary Fig. 1) and contains a superoxide $\mathrm{O}_{2}^{-} \bullet$ unit (O-O bond: 137 pm; Fig. 5). The existence of $\mathrm{O}_{2}^{-}$unit in $\mathrm{RhAl}_{2} \mathrm{O}_{6}^{+}$is consistent with the appearance of $\mathrm{RhAl}_{2} \mathrm{O}_{4} \mathrm{~N}_{2}^{+}$and $\mathrm{RhAl}_{2} \mathrm{O}_{4} \mathrm{CO}^{+}$(or $\mathrm{RhAl}_{2} \mathrm{O}_{4}$ $(\mathrm{CO})_{2}^{+}$) on the interaction of $\mathrm{RhAl}_{2} \mathrm{O}_{6}^{+}$with $\mathrm{N}_{2}$ and $\mathrm{CO}$ (Fig. 1a-d), respectively. Supplementary Figs 7 and 8 show that the Al-site adsorption contributes to the displacement of the $\mathrm{O}_{2}^{-} \cdot$ unit in $\mathrm{RhAl}_{2} \mathrm{O}_{6}^{+}$by $\mathrm{N}_{2}$ or $\mathrm{CO}$ and both reactions are calculated to be thermodynamically and kinetically favourable, and $\mathrm{CO}$ displacement is more facile than $\mathrm{N}_{2}$ displacement. This is consistent with the relatively higher intensity of $\mathrm{RhAl}_{2} \mathrm{O}_{4} \mathrm{CO}^{+}$ (or $\mathrm{RhAl}_{2} \mathrm{O}_{4}(\mathrm{CO})_{2}^{+}$) than $\mathrm{RhAl}_{2} \mathrm{O}_{4} \mathrm{~N}_{2}^{+}$observed in the experiment (Fig. 1a-d). The positively charged $\mathrm{Rh}$ in $\mathrm{RhAl}_{2} \mathrm{O}_{6}^{+}$ (natural charge: $+1.14 \mathrm{e}$ ) can trap $\mathrm{CO}$ tightly at the first step (I1, $\Delta H_{0}=-1.49 \mathrm{eV}$; Fig. 5) and then the oxidation of CO $(\mathrm{I} 1 \rightarrow \mathrm{TS} 1 \rightarrow \mathrm{I} 2)$ by the highly reactive atomic oxygen radical
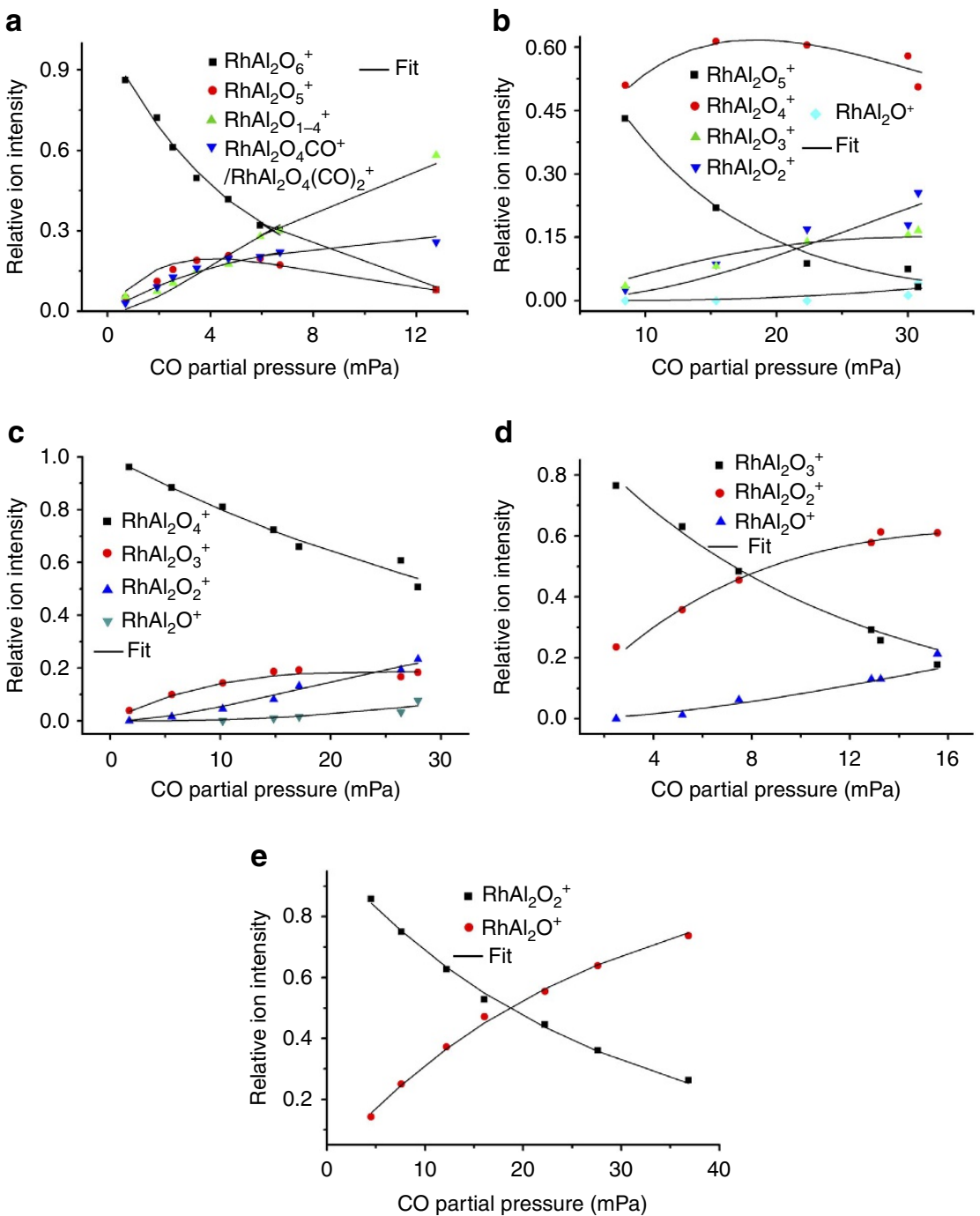

Figure 3 | Reaction kinetics. Variation of ion intensities with respect to the partial pressures of $\mathrm{CO}$ in $\mathrm{RhAl}_{2} \mathrm{O}_{m}^{+}(m=6-2)+\mathrm{CO}$ are shown $(\mathbf{a}-\mathbf{e})$. The solid lines are fitted to the experimental data points by the least-square procedure. The $\mathrm{Rh}^{+}(1,0,0)$ ions (Fig. 2) are mostly generated during cooling of the $\mathrm{RhAl}_{2} \mathrm{O}_{3}^{+}$and $\mathrm{RhAl}_{2} \mathrm{O}_{2}^{+}$cluster ions through collisions with He gas in the ion trap reactor; thus, the ion intensity of $\mathrm{Rh}^{+}$(nearly independent on the CO partial pressure) is excluded in the fitting. See Supplementary Table 1 for details of the determined rate constant values. 
anion $\mathrm{O}^{-} \bullet$ (ref. 31) takes place. Direct $\mathrm{CO}$ oxidation by the $\mathrm{O}_{2}^{-} \bullet$ unit has to suffer from a positive barrier of $0.03 \mathrm{eV}$, which is much less favourable than the oxidation by $\mathrm{O}^{-} \bullet$. The $\mathrm{Rh}$ atom in product $\mathrm{RhAl}_{2} \mathrm{O}_{5}^{+}$(denoted as ${ }^{P} \mathrm{RhAl}_{2} \mathrm{O}_{5}^{+}$, the structure of which is different from the lowest energy structure; Supplementary Fig. 2) can capture another CO tightly (I3, binding energy of $-2.18 \mathrm{eV}$ ). Formation of the bent $\mathrm{CO}_{2}$ is the bottleneck $(\mathrm{I} 3 \rightarrow \mathrm{TS} 2 \rightarrow \mathrm{I} 4)$ for $\mathrm{CO}$ oxidation by ${ }^{P} \mathrm{RhAl}_{2} \mathrm{O}_{5}{ }^{+}$. This step is to subject to a barrier of $1.26 \mathrm{eV}$. The subsequent steps follow a nearly downhill pathway characterized by small barriers to yield $\mathrm{RhAl}_{2} \mathrm{O}_{4}^{+}$and $\mathrm{CO}_{2}$ (Supplementary Fig. 9). Furthermore, theoretical calculations show that the energy of the critical transition state for reaction $\mathrm{RhAl}_{2} \mathrm{O}_{5}^{+}+\mathrm{CO}(-0.47 \mathrm{eV}$; Supplementary Fig. 10) is lower with respect to that for reaction $\mathrm{RhAl}_{2} \mathrm{O}_{6}^{+}+\mathrm{CO}$ (TS1, $-0.37 \mathrm{eV}$; Fig. 5). This can well interpret the more reactive behaviour of the cluster source-generated $\mathrm{RhAl}_{2} \mathrm{O}_{5}^{+}$than $\mathrm{RhAl}_{2} \mathrm{O}_{6}^{+}$in the experiment.

The key step for the transfer of five oxygen atoms from $\mathrm{RhAl}_{2} \mathrm{O}_{6}^{+}$to $\mathrm{CO}$ lies in the facile dissociation of the $\mathrm{O}_{2}^{-} \cdot$ unit in ${ }^{P} \mathrm{RhAl}_{2} \mathrm{O}_{5}^{+}$. Dissociation of the chemically adsorbed molecular

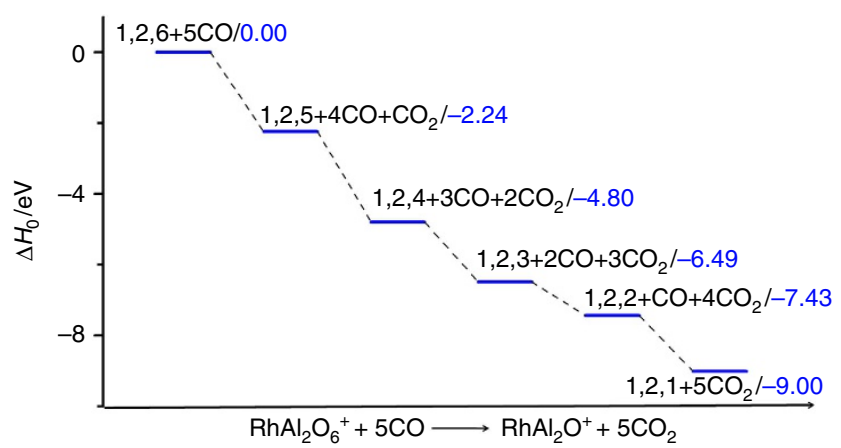

Figure 4 | Reaction thermodynamics. Density functional theory (DFT)calculated thermodynamic data for $\mathrm{CO}$ oxidation by $\mathrm{RhAl}_{2} \mathrm{O}_{2-6}+$. The energies are zero-point vibration-corrected in unit of $\mathrm{eV}$.
$\mathrm{O}_{2}$ (superoxide $\mathrm{O}_{2}^{-} \bullet$ or peroxide $\mathrm{O}_{2}^{2-}$ ) is often considered to be the crucial step in oxidation reactions ${ }^{32}$. Recent gas-phase studies indicated that a single $\mathrm{Au}$ atom in $\mathrm{AuTi}_{3} \mathrm{O}_{8}^{-22}$ is not enough to promote the dissociation of the $\mathrm{O}_{2}^{2-}$ unit, while the $\mathrm{Au}$ dimer in $\mathrm{Au}_{2} \mathrm{VO}_{4}^{-}$can promote $\mathrm{O}_{2}^{2-}$ unit dissociation or direct participation in $\mathrm{CO}$ oxidation ${ }^{25}$. In this study, a single $\mathrm{Rh}$ atom in ${ }^{P} \mathrm{RhAl}_{2} \mathrm{O}_{5}^{+}$can promote the dissociation of the $\mathrm{O}_{2}^{-} \cdot$ unit and the process is much more favourable than $\mathrm{CO}_{2}$ desorption (Fig. 5). This is rationalized by the strong $\mathrm{Rh}-\mathrm{C}$ multiple bonds $(5.97 \mathrm{eV})^{33}$ and the strong $\mathrm{Rh}-\mathrm{O}$ bond $(4.16 \mathrm{eV})^{34}$. Thus, the $\mathrm{Al}-\mathrm{O}_{2}^{-} \bullet$ unit in $\mathrm{I} 4$ can approach the $\mathrm{Rh}$ atom favourably to form structure $\mathrm{Al}-\mathrm{O}_{2}{ }^{2}-\cdots \mathrm{Rh}-\mathrm{CO}_{2}$ in $\mathrm{I} 5$. The elongation of the $\mathrm{O}-\mathrm{O}$ bond from $137 \mathrm{pm}$ in $\mathrm{I} 4$ to $147 \mathrm{pm}$ in $\mathrm{I} 5$ is a good indicator for the activation of the superoxide $\mathrm{O}_{2}^{-} \bullet$ to peroxide $\mathrm{O}_{2}^{2-}$ unit. The structure of I5 is crucial to induce further electron flowing into the $\mathrm{O}_{2}^{2-}$ unit from both of the $\mathrm{Rh}$ atom and the $\mathrm{CO}_{2}$ unit (Fig. 5), and then the $\mathrm{O}_{2}^{2-}$ unit can be dissociated favourably to produce $\mathrm{O}^{2-}-\mathrm{Al}-\mathrm{O}^{2-}-\mathrm{Rh}-\mathrm{CO}_{2}(\mathrm{I} 5 \rightarrow \mathrm{TS} 4 \rightarrow \mathrm{I} 6)$. Direct oxidation of $\mathrm{CO}$ by the $\mathrm{O}_{2}^{-} \bullet$ unit in ${ }^{P} \mathrm{RhAl}_{2} \mathrm{O}_{5}^{+}$ (Supplementary Fig. 9) is less favourable than the pathway in Fig. 5. This is consistent with previous study that instead of the direct participation in $\mathrm{CO}$ oxidation, molecular oxygen adsorbs at the interface between the oxygen vacancy and the single $\mathrm{Rh}$ site and then is followed by facile dissociation ${ }^{35}$. Release of three additional oxygen atoms from the resulting $\mathrm{RhAl}_{2} \mathrm{O}_{4}^{+}$to $\mathrm{CO}$ are calculated to be thermodynamically and kinetically favourable (Supplementary Figs 11-13). In each of these OAT steps, Rh atom functions as the preferred trapping site to anchor $\mathrm{CO}$ and then delivers $\mathrm{CO}$ for oxidation by the oxygen atoms in direct connection with $\mathrm{Rh}$. The theoretical calculations well interpret the unique reactivity of $\mathrm{RhAl}_{2} \mathrm{O}_{6}^{+}$observed in the experiment.

\section{Discussion}

Metal-mediated OAT reaction is usually accompanied with the reduction of central metal by electrons that are stored originally in the removed oxygen atoms ${ }^{36}$ (equation (2)).

$$
\mathrm{M}^{n+} \mathrm{O}_{x}+\mathrm{R} \rightarrow \mathrm{M}^{(n-2)+} \mathrm{O}_{x-1}+\mathrm{RO}
$$

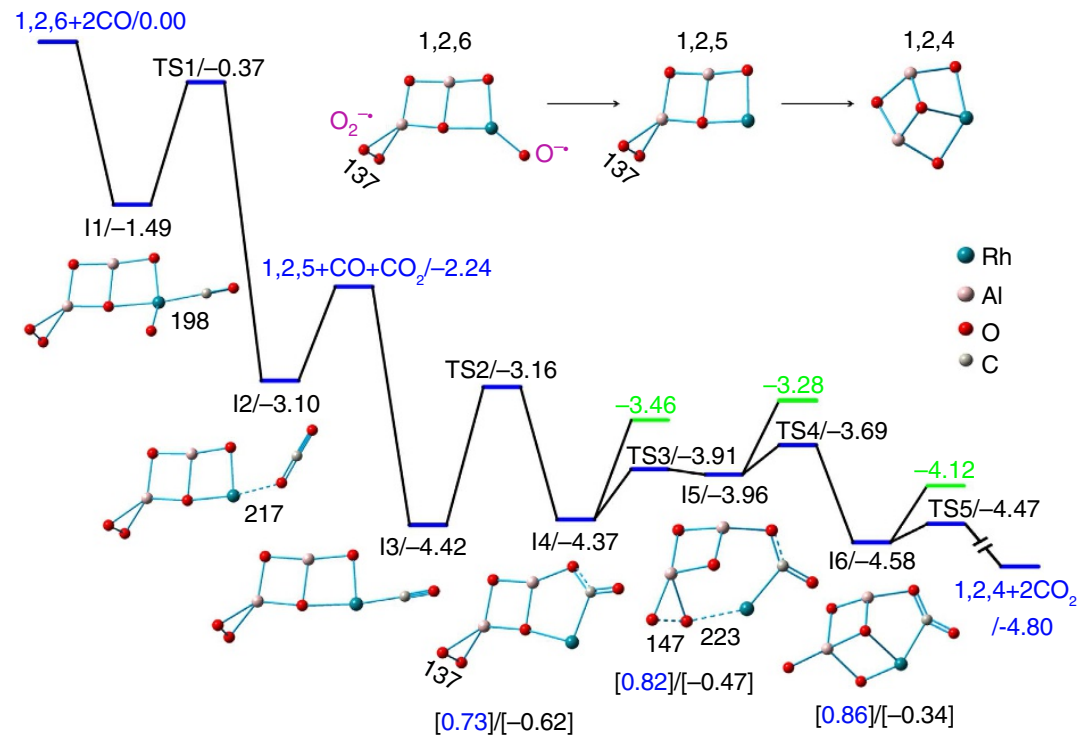

Figure 5 | Structures and reaction mechanisms. Density functional theory (DFT)-calculated potential energy profiles for the oxidation of the first two $\mathrm{CO}$ molecules by $\mathrm{RhAl}_{2} \mathrm{O}_{6}^{+}$. The lowest energy structure of $\mathrm{RhAl}_{2} \mathrm{O}_{6}^{+}(1,2,6)$ and the products ${ }^{P} \mathrm{RhAl}_{2} \mathrm{O}_{5}^{+}(1,2,5)$ and $\mathrm{RhAl}_{2} \mathrm{O}_{4}^{+}(1,2,4)$ are provided. Symbols $\mathrm{O}_{2}^{-} \cdot$ and $\mathrm{O}^{-} \bullet$ denote superoxide and atomic oxygen radical species, respectively. The relative energies for intermediates (I1-16) and transition states (TS1-TS5) are in unit of eV. Structures of I1-16 are shown. Bond lengths are given in pm. The values in green show the relative energies for direct $\mathrm{CO}_{2}$ desorption from 14 to 16. The values in the square brackets show the natural charges on Rh (blue) and $\mathrm{CO}_{2}$ unit (black). See also Supplementary Figs $9-13$ for more information. 
The positively charged metal centre is crucial to provide not only the characteristic site for the adsorption of CO (ref. 37) but also the oxidative centre to accept electrons. Recent gas-phase studies highlighted that the cleavage of $\mathrm{Au}-\mathrm{O}$ bond and the formation of $\mathrm{Au}-M$ bond $(M=\mathrm{Al}, \mathrm{V}, \mathrm{Ti}$, and $\mathrm{Fe})$ is of great importance in $\mathrm{CO}$ oxidation by Au-doped clusters ${ }^{22-25}$. However, each of the $\mathrm{Au}$-doped clusters can oxidize only one or at most two $\mathrm{CO}$ molecules and then the polarity conversion of $\mathrm{Au}$ atom from positive to negative takes place because of the formation of the reductive $\mathrm{Au}-M$ bond. In sharp contrast, natural charge analysis demonstrates that after the transfer of four oxygen atoms from $\mathrm{RhAl}_{2} \mathrm{O}_{6}^{+}$to $\mathrm{CO}$, the $\mathrm{Rh}$ atom is still positively charged $(+0.53 e$, Fig. 6) in product $\mathrm{RhAl}_{2} \mathrm{O}_{2}^{+}$, which can also oxidize a $\mathrm{CO}$ molecule. The natural charge on $\mathrm{Rh}$ atom is decreased from $+1.14 e$ in $\mathrm{RhAl}_{2} \mathrm{O}_{6}^{+}$to $+1.00 e$ in ${ }^{P} \mathrm{RhAl}_{2} \mathrm{O}_{5}^{+}$after the oxidation of the first $\mathrm{CO}$. In this step, Rh acts as the primary centre to accumulate the electron that is localized originally on $\mathrm{O}^{-} \bullet$ radical, as shown from the change of spin density distribution, $\mathrm{RhAl}_{2} \mathrm{O}_{6}^{+}$versus ${ }^{P} \mathrm{RhAl}_{2} \mathrm{O}_{5}^{+}$. However, the $\mathrm{Rh}$ atom is re-oxidized in product $\mathrm{RhAl}_{2} \mathrm{O}_{4}^{+}(+1.15 e)$ after the oxidation of the second $\mathrm{CO}$ due to the dissociation of the $\mathrm{O}_{2}^{-} \cdot$ unit (I4 $\rightarrow$ I5 $\rightarrow$ I6; Fig. 5). This step is crucial to recover the oxidative reactivity of Rh. In situ Raman spectroscopic study also demonstrated that supported $\mathrm{Rh}$ oxide can oxidize $\mathrm{CO}$ and then the $\mathrm{Rh}$ oxide is subsequently re-oxidized by the oxygen atoms from oxide support ${ }^{7}$. This phenomenon can be traced back to the well-fitting strength of $\mathrm{Rh}-\mathrm{O}$ bond $(4.16 \mathrm{eV})^{34}$, which is strong enough to promote the dissociation of the $\mathrm{O}_{2}^{-} \cdot$ unit in ${ }^{P} \mathrm{RhAl}_{2} \mathrm{O}_{5}^{+}$and prevent the formation of the reductive $\mathrm{Rh}-\mathrm{Al}$ bond $\left(3.26 \mathrm{eV}\right.$, by theoretical calculation) in $\mathrm{RhAl}_{2} \mathrm{O}_{2-6}{ }^{+}$but at the same time is relatively weak to deliver oxygen atoms to oxidize CO (O-CO: $5.52 \mathrm{eV})^{38}$. Previous studies show that $\mathrm{Rh}$ prefers to coordinate not only with the surface oxygen atoms but also the subsurface oxygen in oxide support ${ }^{35}$. The strong $\mathrm{Rh}-\mathrm{O}$ bond inhibits the migration of $\mathrm{Rh}$ atom to the oxygen vacancy and remains positively charged. Using high-resolution in situ $\mathrm{X}$-ray diffraction and transmission electron microscopy, Stierle and colleagues ${ }^{1}$ reported the reversible and oxygen-induced shape transformation of $\mathrm{Rh}$ nanoparticles by the formation of $\mathrm{O}-\mathrm{Rh}-\mathrm{O}$ surface oxide during the cycle of catalytic $\mathrm{CO}$ oxidation. In contrast, the stronger $\mathrm{Au}-\mathrm{M}(\mathrm{Au}-\mathrm{Al}=3.37 \mathrm{eV}$ (ref. 39), $\mathrm{Au}-\mathrm{V}=2.49 \mathrm{eV}$ (ref. 38) and $\mathrm{Au}-\mathrm{Ti}=2.56 \mathrm{eV}$ (by theoretical calculation)) than $\mathrm{Au}-\mathrm{O}$ bond $(2.27 \mathrm{eV})^{34}$ facilitates the formation of the reductive $\mathrm{Au}-\mathrm{M}$ bond after the oxidation of only one or two CO molecules.

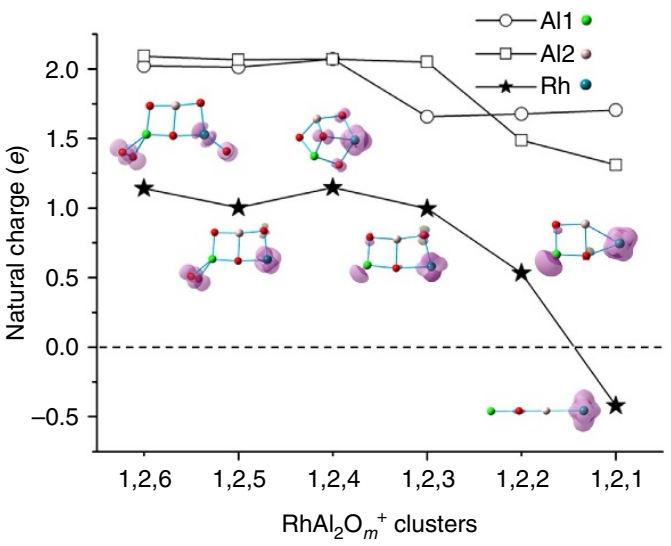

Figure 6 | Natural charge. Density functional theory (DFT)-calculated natural charges (e) on the Rh atom and $\mathrm{Al}$ atoms in $\mathrm{RhAl}_{2} \mathrm{O}_{1-6}{ }^{+}$. The spin density distributions on individual atoms are shown in the purple isosurfaces.
The negatively charged $\mathrm{Rh}$ has been theoretically predicted ${ }^{40}$ and experimentally postulated ${ }^{41}$. The $\mathrm{RhAl}_{2} \mathrm{O}^{+}$cluster is a linear structure ( $\mathrm{Al}-\mathrm{O}-\mathrm{Al}-\mathrm{Rh})$ and the single oxygen atom is sandwiched between two $\mathrm{Al}$ atoms. This structure with triplet spin state has been confirmed to be the lowest energy isomer of $\mathrm{RhAl}_{2} \mathrm{O}^{+}$by more accurate $\mathrm{CCSD}(\mathrm{T})$ calculation (Supplementary Fig. 6). The two unpaired electrons are mainly localized on the $\mathrm{Rh}$ atom $\left(\sim 1.83 \mu_{\mathrm{B}}\right.$, Fig. 6$)$, indicating that such $\mathrm{Rh}$ atom can be considered to be $\mathrm{Rh}^{-1}\left(4 d^{9} 5 s^{1}\right)$. The electron configuration calculations $\left(4 d^{8.75} 5 s^{0.64} 5 p^{0.03}\right)$ provide solid evidence for the negatively charged $\mathrm{Rh}$ in $\mathrm{RhAl}_{2} \mathrm{O}^{+}$. Thus, the oxidation state of $\mathrm{Rh}$ changes from +2.5 in $\mathrm{RhAl}_{2} \mathrm{O}_{6}^{+}$to -1 in $\mathrm{RhAl}_{2} \mathrm{O}^{+}$(calculated based on the distribution of spin density; Fig. 6) during the transfer of five oxygen atoms from $\mathrm{RhAl}_{2} \mathrm{O}_{6}^{+}$to $\mathrm{CO}$. This rather large range of $\mathrm{Rh}$ oxidation state changes in chemical reactions has rarely been reported (the $\mathrm{Au}$ oxidation state changes from +1 to -1 ), covering from cationic to anionic, and it is the driving force to accumulate the electrons that are stored originally in the released oxygen atoms and promotes the unique oxidative reactions to proceed.

In conclusion, we have demonstrated that a single atom of $\mathrm{Rh}$ can unexpectedly promote the transfer of five oxygen atoms to oxidize $\mathrm{CO}$ from a nine-atom cluster $\mathrm{RhAl}_{2} \mathrm{O}_{6}^{+}$. This study leads a leap ahead towards OAT reactions in the field of cluster science and represents an important step to understand the participation of lattice oxygen promoted by noble metals. The preferable $\mathrm{Rh}-\mathrm{O}$ rather than the reductive $\mathrm{Rh}-\mathrm{Al}$ bond formation together with the capability of $\mathrm{Rh}$ to accumulate the large amounts of electrons are crucial factors to drive the unique reactions. This gas-phase study reveals the molecular-level origin for the puzzling experimental observation that trace amounts of $\mathrm{Rh}$ can promote the reactivity of lattice oxygen of $\mathrm{Al}_{2} \mathrm{O}_{3}$ (refs 4,5,9), a chemically very inert material.

\section{Methods}

Cluster generation and reactivity detection. The $\mathrm{Rh}_{x} \mathrm{Al}_{y} \mathrm{O}_{z}^{+}$cluster ions were generated by laser ablation of a mixed-metal disk compressed with $\mathrm{Rh}$ and $\mathrm{Al}$ powders (molar radio $\mathrm{Rh} / \mathrm{Al}=1 / 1$ ) in the presence of $\mathrm{O}_{2}(0.4 \%)$ seeded in a $\mathrm{He}$ carrier gas with a backing pressure of 6.0 standard atmospheres. The cluster ions of interest were mass selected using a quadrupole mass filter and then entered into a linear ion trap (LIT) reactor, where they were cooled by collisions with a pulse of $\mathrm{He}$ gas and then interacted with a pulse of $5 \%$ (for reactions $\mathrm{RhAl}_{2} \mathrm{O}_{m}^{+}(m=2-5)$ $+\mathrm{CO}$ ) or $2 \%$ (for reaction $\mathrm{RhAl}_{2} \mathrm{O}_{6}^{+}+\mathrm{CO}$ ) $\mathrm{CO}$ seeded in $\mathrm{He}$ for around $0.6 \sim 1.1 \mathrm{~ms}$. The temperature of cooling gas $(\mathrm{He})$, reactant gases $\left(\mathrm{CO}\right.$ or $\left.\mathrm{N}_{2}\right)$ and the LIT reactor was around $298 \mathrm{~K}$. The cluster ions ejected from the LIT were detected by a reflector time-of-flight mass spectrometer. The details of running the time-of-flight mass spectrometer ${ }^{42}$, quadrupole mass filter ${ }^{43}$ and the LIT $^{44}$ can be found in our previous works.

Rate constant fitting. Equation (3) was used to determine the pseudo-first-order rate constants $\left(k_{1}\right)$ of cluster reactions in an ion trap reactor ${ }^{44}$, in which $I_{\mathrm{R}}$ is the signal intensity of the reactant cluster ions, $I_{\mathrm{T}}$ is the total ion intensity including product ion contribution, $k_{\mathrm{B}}$ is the Boltzmann constant, $T$ is the temperature $(\sim 298 \mathrm{~K}), t_{\mathrm{R}}$ is the reaction time and $P$ is the effective pressure of the reactant gas in the ion trap reactor.

$$
\ln \frac{I_{\mathrm{R}}}{I_{\mathrm{T}}}=-k_{1} \frac{P}{k_{\mathrm{B}} T} t_{\mathrm{R}}
$$

To calculate the reaction efficiencies (the possibilities of reaction on each collision), the collision rate constants were calculated on the basis of the surface charge capture model developed in the literature ${ }^{30}$. It is noteworthy that for reaction $\mathrm{RhAl}_{2} \mathrm{O}_{5}^{+}+\mathrm{CO}$, the relative ion intensity of $\mathrm{RhAl}_{2} \mathrm{O}_{5}^{+}$is the reactive component generated in the experiment and the unreactive component is not included. The unreactive component of $\mathrm{RhAl}_{2} \mathrm{O}_{5}^{+}$could be well-fitted by equation $(4)^{45}$.

$$
I_{\mathrm{R}}=x_{\text {inert }}+\left(1-x_{\text {inert }}\right) \times \exp \left(-k_{1} \frac{P}{k_{\mathrm{B}} T} t_{\mathrm{R}}\right)
$$

in which $x_{\text {inert }}$ is the relative intensity of the unreactive component of $\mathrm{RhAl}_{2} \mathrm{O}_{5}^{+}$ and $k_{1}$ is the pseudo-first-order rate constant of the reactive component of $\mathrm{RhAl}_{2} \mathrm{O}_{5}^{+}$. The $x_{\text {inert }}$ was determined to be about $12 \%$, indicating that the experimentally generated $\mathrm{RhAl}_{2} \mathrm{O}_{5}^{+}$may have isomers that are not or less reactive with $\mathrm{CO}$ 
Computational details. Density functional theory calculations using the Gaussian 09 (ref. 46) programme were carried out to investigate the mechanistic details on the oxidation of five $\mathrm{CO}$ molecules by a nine-atom rhodium-aluminum oxide cluster $\left(\mathrm{RhAl}_{2} \mathrm{O}_{6}^{+}\right)$. To find an appropriate functional for the $\mathrm{Rh}-\mathrm{Al}-\mathrm{O}$ system, the bond dissociation energies of $\mathrm{Rh}-\mathrm{O}, \mathrm{Rh}-\mathrm{C}, \mathrm{Al}-\mathrm{O}, \mathrm{O}-\mathrm{O}, \mathrm{Rh}-\mathrm{Al}$ and $\mathrm{O}-\mathrm{CO}$ were computed by various functionals and compared with available experimental data (Supplementary Table 2). It turns out that M06L ${ }^{47}$ was the best overall; thus, the results by M06L were given throughout the work. The TZVP basis set ${ }^{48}$ for $\mathrm{Al}$, $\mathrm{C}$ and $\mathrm{O}$ atoms and a D95V basis set ${ }^{49}$ combined with the Stuttgart/Dresden relativistic effective core potential (denoted as SDD in Gaussian software) for $\mathrm{Rh}$ atom were used in all the calculations. A Fortran code based on a genetic algorithm ${ }^{50}$ was used to generate initial guess structures of $\mathrm{RhAl}_{2} \mathrm{O}_{1-6}{ }^{+}$. The reaction mechanisms were studied for $\mathrm{RhAl}_{2} \mathrm{O}_{6}^{+}+5 \mathrm{CO} \rightarrow \mathrm{RhAl}_{2} \mathrm{O}^{+}+5 \mathrm{CO}_{2}$. The relaxed potential energy surface scan was used extensively to obtain good guess structures for intermediates and transition states along the pathways. The transition states were optimized using the Berny algorithm ${ }^{51}$. Intrinsic reaction coordinate calculations ${ }^{52,53}$ were performed so that each transition state connects two appropriate local minima. Vibrational frequency calculations were carried out to check that intermediates and transition state have zero and only one imaginary frequency, respectively.

\section{References}

1. Nolte, P. et al. Shape changes of supported Rh nanoparticles during oxidation and reduction cycles. Science 321, 1654-1658 (2008).

2. Grass, M. E. et al. A reactive oxide overlayer on rhodium nanoparticles during $\mathrm{CO}$ oxidation and its size dependence studied by in situ ambient-pressure $\mathrm{X}$-ray photoelectron spectroscopy. Angew. Chem. Int. Ed. 47, 8893-8896 (2008).

3. Ligthart, D. A. J. M., van Santen, R. A. \& Hensen, E. J. M. Supported rhodium oxide nanoparticles as highly active $\mathrm{CO}$ oxidation catalysts. Angew. Chem. Int. Ed. 50, 5306-5310 (2011).

4. Karin, C. B., Wohlrab, S., Rodemerck, U. \& Kondratenko, E. V. The tremendous effect of trace amounts of $\mathrm{Rh}$ on redox and catalytic properties of $\mathrm{CeO}_{2}-\mathrm{TiO}_{2}$ and $\mathrm{Al}_{2} \mathrm{O}_{3}$ in $\mathrm{CH}_{4}$ partial oxidation. Catal. Commun. 18, 121-125 (2012)

5. Karin, C. B. et al. Tailored noble metal nanoparticles on $\gamma-\mathrm{Al}_{2} \mathrm{O}_{3}$ for high temperature $\mathrm{CH}_{4}$ conversion to syngas. ChemCatChem. 4, 1368-1375 (2012).

6. Karelovic, A. \& Ruiz, P. Improving the hydrogenation function of $\mathrm{Pd} / \gamma-\mathrm{Al}_{2} \mathrm{O}_{3}$ catalyst by $\mathrm{Rh} / \gamma-\mathrm{Al}_{2} \mathrm{O}_{3}$ addition in $\mathrm{CO}_{2}$ methanation at low temperature. ACS Catal. 3, 2799-2812 (2013).

7. Song, W., Jansen, A. P. J., Degirmenci, V., Ligthart, D. A. J. M. \& Hensen, E. J. M. A computational study of the mechanism of $\mathrm{CO}$ oxidation by a ceria supported surface rhodium oxide layer. Chem. Commun. 49, 3851-3853 (2013).

8. Duarte, R. B., Krumeich, F. \& van Bokhoven, J. A. Structure, activity, and stability of atomically dispersed $\mathrm{Rh}$ in methane stream reforming. ACS Catal. 4, 1279-1286 (2014).

9. Kondratenko, V. A., Karin, C. B. \& Kondratenko, E. V. Partial oxidation of methane to syngas over $\gamma-\mathrm{Al}_{2} \mathrm{O}_{3}$-supported $\mathrm{Rh}$ nanoparticles: kinetic and mechanistic origins of size effect on selectivity and activity. ACS Catal. 4, 3136-3144 (2014).

10. Castleman, Jr A. W. \& Jena, P. Clusters: a bridge between disciplines. Proc. Natl Acad. Sci. USA 103, 10552-10553 (2006).

11. O'Hair, R. A. J. \& Khairallah, G. N. Gas phase ion chemistry of transition metal clusters: production, reactivity, and catalysis. J. Clust. Sci. 15, 331-363 (2004).

12. Böhme, D. K. \& Schwarz, H. Gas-phase catalysis by atomic and cluster metal ions: the ultimate single-site catalysts. Angew. Chem. Int. Ed. 44, 2336-2354 (2005).

13. Burgert, R. et al. Spin conservation accounts for aluminum cluster anion reactivity pattern with $\mathrm{O}_{2}$. Science $319,438-442$ (2008).

14. Gong, Y. \& Zhou, M. Spectroscopic and theoretical studies of transition metal oxides and dioxygen complexes. Chem. Rev. 109, 6765-6808 (2009).

15. Roach, P. J., Woodward, W. H., Castleman, Jr A. W., Reber, A. C. \& Khanna, S. N. Complementary active sites cause size-selective reactivity of aluminum cluster anions with water. Science 323, 492-495 (2009).

16. Lang, S. M. \& Bernhardt, T. M. Gas phase metal cluster model systems for heterogeneous catalysis. Phys. Chem. Chem. Phys. 14, 9255-9269 (2012).

17. Asmis, K. R. Structure characterization of metal oxide clusters by vibrational spectroscopy: possibilities and prospects. Phys. Chem. Chem. Phys. 14, 9270-9281 (2012).

18. Blagojevic, V., Orlova, G. \& Bohme, D. K. O-atom transport catalysis by atomic cations in the gas phase: reduction of $\mathrm{N}_{2} \mathrm{O}$ by CO. J. Am. Chem. Soc. 127, 3545-3555 (2005).

19. Liu, Q. Y. \& He, S. G. Oxidation of carbon monoxide on atomic clusters. Chem. J. Chin. Univ. 35, 665-688 (2014).

20. Schwarz, H. Doping effects in cluster-mediated bond activation. Angew. Chem. Int. Ed. 54, 10090-10100 (2015).
21. Freund, H. J., Meijer, G., Scheffler, M., Schlögl, R. \& Wolf, M. CO oxidation as prototypical reaction for heterogeneous processes. Angew. Chem. Int. Ed. 50, 10064-10094 (2011).

22. Li, X. N., Yuan, Z. \& He, S. G. CO oxidation promoted by gold atoms supported on titanium oxide cluster anions. J. Am. Chem. Soc. 136, 3617-3623 (2014).

23. Li, Z. Y., Yuan, Z., Li, X. N., Zhao, Y. X. \& He, S. G. CO oxidation catalyzed by single gold atoms supported on aluminum oxide clusters. J. Am. Chem. Soc. 136, 14307-14313 (2014).

24. Yuan, Z., Li, X. N. \& He, S. G. CO oxidation promoted by gold atoms loosely attached in $\mathrm{AuFeO}_{3}^{-}$cluster anions. J. Phys. Chem. Lett. 5, 1585-1590 (2014).

25. Wang, L. N. et al. $\mathrm{CO}$ oxidation promoted by the gold dimer in $\mathrm{Au}_{2} \mathrm{VO}_{3}^{-}$and $\mathrm{Au}_{2} \mathrm{VO}_{4}^{-}$clusters. Angew. Chem. Int. Ed. 54, 11720-11724 (2015).

26. Li, X. N., Yuan, Z., Meng, J. H., Li, Z. Y. \& He, S. G. Catalytic CO oxidation on single Pt-atom doped aluminum oxide clusters: electronegativity-ladder effect. J. Phys. Chem. C 119, 15414-15420 (2015).

27. Johnson, G. E., Tyo, E. C. \& Castleman, Jr A. W. Oxidation of CO by aluminum oxide cluster ions in the gas phase. J. Phys. Chem. A 112, 4732-4735 (2008).

28. Li, S., Mirabal, A., Demuth, J., Wöste, L. \& Siebert, T. A complete reactant-product analysis of the oxygen transfer reaction in $\left[\mathrm{V}_{4} \mathrm{O}_{11} \cdot \mathrm{C}_{3} \mathrm{H}_{6}\right]^{-}$: a cluster complex for modeling surface activation and reactivity. J. Am. Chem. Soc. 130, 16832-16833 (2008).

29. Li, S., Demuth, J., Mirabal, A., Wöste, L. \& Siebert, T. On the role of thermal activation in selective photochemistry: mechanistic insight into the oxidation of propene on the $\mathrm{V}_{4} \mathrm{O}_{11}^{-1}$ cluster. Phys. Chem. Chem. Phys. 14, 148-156 (2012).

30. Kummerlöwe, G. \& Beyer, M. K. Rate estimates for collisions of ionic clusters with neutral reactant molecules. Int. J. Mass Spectrom. 244, 84-90 (2005).

31. Ma, J. B. et al. Reactivity of atomic oxygen radical anions bound to titania and zirconia nanoparticles in the gas phase: low-temperature oxidation of carbon monoxide. J. Am. Chem. Soc. 136, 2991-2998 (2013).

32. Panov, G. I., Dubkov, K. A. \& Starokon, E. V. Active oxygen in selective oxidation catalysis. Catal. Today 117, 148-155 (2006).

33. Shim, I. \& Gingerich, K. A. Electronic structure and bonding in the RhC molecule by all-electron ab initio HF-CI calculations and mass spectrometric measurements. J. Chem. Phys. 81, 5937-5944 (1984).

34. Pedley, J. B. \& Marshall, E. M. Thermochemical data for gaseous monoxides. J. Phys. Chem. Ref. Data 12, 967-1031 (1983).

35. Song, W., Jansen, A. P. J. \& Hensen, E. J. M. A computational study of the influence of the ceria surface termination on the mechanism of $\mathrm{CO}$ oxidation of isolated Rh atoms. Faraday Discuss 162, 281-292 (2013).

36. Holm, R. H. Metal-centered oxygen atom transfer reactions. Chem. Rev. 87, 1401-1449 (1987).

37. Guzman, J. \& Gates, B. C. Catalysis by supported gold: correlation between catalytic activity for $\mathrm{CO}$ oxidation and oxidation states of gold. J. Am. Chem. Soc. 126, 2672-2673 (2004).

38. Luo, Y. P. Comprehensive Handbook of Chemical Bond Energies. pp. 9-56 (CRC Press, 2007).

39. Cuthill, A. M., Fabian, D. J. \& Shen, S. S. S. Bond dissociation energies of the metallic vapor species aluminum-silver and aluminum-gold measured by Knudsen-Cell mass spectrometry. J. Phys. Chem. 77, 2008-2011 (1973).

40. Gómez, T., Florez, E., Rodriguez, J. A. \& Illas, F. Theoretical analysis of the adsorption of late transition-metal atoms on the (001) surface of early transition-meal carbides. J. Phys. Chem. C 114, 1622-1626 (2010).

41. Zafeiratos, S., Nehasil, V. \& Ladas, S. X-ray photoelectron spectroscopy study of rhodium particle growth on different alumina surfaces. Surf. Sci 433-435, 612-616 (1999).

42. Wu, X. N., Xu, B., Meng, J. H. \& He, S. G. C-H bond activation by nanosized scandium oxide clusters in gas-phase. Int. J. Mass Spectrom. 310, 57-64 (2012).

43. Yuan, Z., Zhao, Y. X., Li, X. N. \& He, S. G. Reactions of $\mathrm{V}_{4} \mathrm{O}_{10}^{+}$cluster ions with simple inorganic and organic molecules. Int. J. Mass Spectrom. 354-355, 105-112 (2013).

44. Yuan, Z. et al. Thermal reactions of $\left(\mathrm{V}_{2} \mathrm{O}_{5}\right)_{n} \mathrm{O}^{-}(n=1-3)$ cluster anions with ethylene and propylene: oxygen atom transfer versus molecular association. J. Phys. Chem. C 118, 14967-14976 (2014).

45. Li, H. F. et al. Methane activation by iron-carbide cluster anions $\mathrm{FeC}_{6}^{-}$. J. Phys. Chem. Lett. 6, 2287-2291 (2015).

46. Frisch, M. J. et al. Gaussian 09, Revision A. 1 (Gaussian, Inc., 2009).

47. Zhao, Y. \& Truhlar, D. G. A new local density functional for main-group thermochemistry, transition metal bonding, thermochemical kinetics, and noncovalent interactions. J. Chem. Phys. 125, 194101 (2006).

48. Schäfer, A., Huber, C. \& Ahlrichs, R. Fully optimized contracted Gaussian basis sets of triple zeta valence quality for atoms Li to Kr. J. Chem. Phys. 100, 5829-5835 (1994).

49. Andrae, D., Häußermann, U., Dolg, M., Stoll, H. \& Preuß, H. Energy-adjusted ab initio pseudopotentials for the second and trird row transition elements. Theor. Chim. Acta 77, 123-141 (1990).

50. Ding, X. L., Li, Z. Y., Meng, J. H., Zhao, Y. X. \& He, S. G. Density-functional global optimization of $\left(\mathrm{La}_{2} \mathrm{O}_{3}\right)_{n}$ clusters. J. Chem. Phys. 137, 214311 (2012) 
51. Schlegel, H. B. Optimization of equilibrium geometries and transition structures. J. Comput. Chem. 3, 214-218 (1982).

52. Gonzalez, C. \& Schlegel, H. B. An improved algorithm for reaction path following. J. Chem. Phys. 90, 2154-2161 (1989).

53. Gonzalez, C. \& Schlegel, H. B. Reaction path following in mass-weighted internal coordinates. J. Phys. Chem. 94, 5523-5527 (1990).

\section{Acknowledgements}

This work was financially supported by the National Natural Science Foundation of China (Nos 21303215, 21325314, 21273247 and 21573246) and the Major Research Plan of China (No. 2013CB834603).

\section{Author contributions}

The original manuscript, figures, tables and the Supplementary Materials were prepared by X.-N.L. The theoretical calculations were prepared by H.-M.Z. and X.-N.L. The experimental data were prepared by Z.Y. and H.-M.Z. S.-G.H. provided the original idea, helpful discussions and the contribution in the manuscript revision.

\section{Additional information}

Supplementary Information accompanies this paper at http://www.nature.com/ naturecommunications

Competing financial interests: The authors declare no competing financial interests.

Reprints and permission information is available online at http://npg.nature.com/ reprintsandpermissions/

How to cite this article: $\mathrm{Li}, \mathrm{X}$.-N. et al. A nine-atom rhodium-aluminum oxide cluster oxidizes five carbon monoxide molecules. Nat. Commun. 7:11404 doi: $10.1038 /$ ncomms11404 (2016).

(c) (i)

This work is licensed under a Creative Commons Attribution 4.0 International License. The images or other third party material in this article are included in the article's Creative Commons license, unless indicated otherwise in the credit line; if the material is not included under the Creative Commons license, users will need to obtain permission from the license holder to reproduce the material. To view a copy of this license, visit http://creativecommons.org/licenses/by/4.0/ 